\title{
Effect of Gradient of Soil Aeration on Corrosion Rate at Different Depths from Ground Surface
}

\author{
K. Fujihashi ${ }^{\mathrm{a}, \mathrm{b}}$ and W. Oshikawa ${ }^{\mathrm{a}}$ \\ ${ }^{\text {a }}$ Faculty of Engineering, University of the Ryukyus, Nishihara, Okinawa 903-0213, \\ JAPAN \\ ${ }^{\mathrm{b}}$ Department of Technology and Investigation, OKUJI KENSAN Co., LTD., Osaka-city, \\ Osaka 541-0054, JAPAN
}

\begin{abstract}
Soil corrosion around a ground surface was experimentally examined by measuring macrocell current, spontaneous potential, and corrosion weight loss at different depths in soil. An experiment was carried out by placing small electrodes and small test pieces in the depth direction. The results showed that mainly anodic current flowed in the electrode around the ground surface. In addition, the corrosion rate estimated based on weight loss was the highest. Therefore, it is considered that macrocell current influences soil corrosion around the ground surface. However, it appears that the spontaneous potential difference and macrocell current due to the gradient of soil aeration do not contribute significantly to soil corrosion around the ground surface.
\end{abstract}

\section{Introduction}

In recent years, the number of photovoltaic electric power systems has increased considerably in Japan. Reinforced concrete was used as the foundation of these systems. However, currently, these systems have steel pile foundations because they are cheaper and easier to install than reinforced concrete. Conventional steel piles used in civil engineering and construction work are fully buried in soil. In contrast, the steel piles used for the abovementioned systems are not entirely buried in soil. The top of a steel pile used for supporting photovoltaic panels is exposed to the atmosphere and around the atmospheresoil interface (ground surface). Furthermore, the corrosion rate of a conventional steel pile is typically $0.01 \mathrm{~mm} /$ year (one side conversion) irrespective of the soil type (1). However, for steel piles with tops exposed to the atmosphere, such as illumination poles, the corrosion rate around the ground surface is higher than the general corrosion rate $(0.01$ $\mathrm{mm} /$ year). This results in the collapse of these steel piles. However, this problem has not been widely investigated.

We carried out an exposure test and measured corrosion weight loss at different depths. We evaluated the corrosivity of soil by measuring AC impedance using the soil of the exposure test site (2). The results showed that soil corrosion did not occur around all ground surfaces and that soil corrosion did not depend on the corrosivity of soil. It was considered that soil corrosion occurred around the ground surface because of the potential difference and macrocell current due to the gradient of soil aeration. Thus, the potential difference and macrocell current were measured in a simulated environment. The purpose of this 
experiment is to evaluate the contribution of macrocell current due to the gradient of soil aeration on corrosion around the ground surface.

\section{Experimental Method}

\section{Overview of Experimental Equipment}

The schematics of the experimental equipment are shown in Figure 1. The macrocell current, spontaneous potential, impedance, temperature, conductivity, water ratio, and corrosion weight loss in soil were measured by utilizing electrodes, test pieces, and sensors. The cracks caused by the installation of the electrodes, test pieces, and sensors were filled with a sealing material.

The soil used in the experiment was general paddy soil, which is referred to as Arakita soil in Japan. Paddy soil was selected because it was the environment in which corrosion occurred around the ground surface in our previous experiment (2). A soil extract solution was obtained by filtration after shaking $150 \mathrm{~mL}$ of ultrapure water with $75 \mathrm{~g}$ of dissolved soil for $20 \mathrm{~min}$. The chemical analysis results of the soil and soil extract solution are shown in Table 1 and Table 2, respectively.

The soil was fully dried at $160{ }^{\circ} \mathrm{C}$ in a thermostatic oven, pulverized in a mill, and passed through a sieve with a mesh size of $1 \mathrm{~mm}$. Then, deionized water was added to 15 $\mathrm{wt} \%$ of the dried pulverized soil. The soil was poured into the experimental equipment. After each $1 \mathrm{~kg}$ of soil was poured, it was compacted using a home-made rammer (a weight of $1439 \mathrm{~g}$ and a tip diameter $(\phi)$ of $20 \mathrm{~mm}$ ).

The measurements were performed for approximately 6 weeks staring from February 12, 2020. During the measurement period, $117 \mathrm{ml}$ ionized water was added to the experimental equipment 8 times in total.
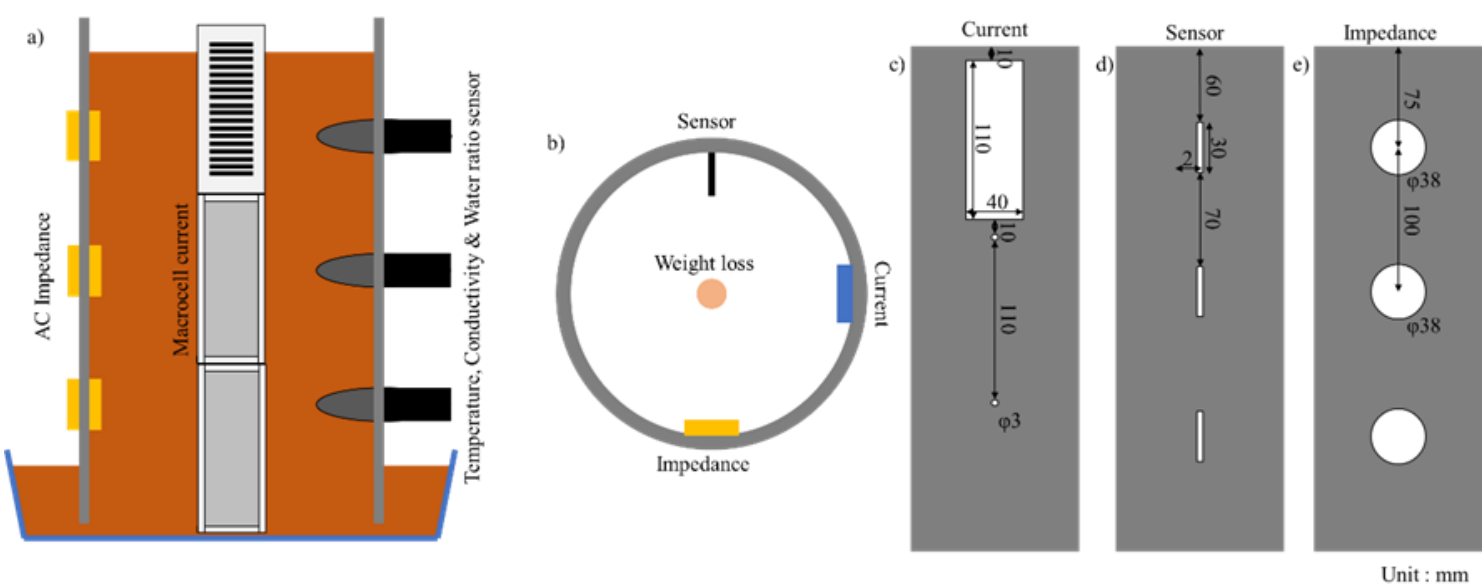

Figure 1. Schematics of experimental equipment. a) Overview, b) top view, and c) side view of macrocell current electrodes. d) Side view of sensors. e) Side view of AC impedance electrodes. 
TABLE I. Chemical Analysis of Soil Used in the Experiment.

\begin{tabular}{ccccccccc}
\hline \multicolumn{8}{c}{ Major Element, wt\% } \\
\hline $\mathbf{C}$ & $\mathbf{O}$ & $\mathbf{M g}$ & $\mathbf{A l}$ & $\mathbf{S i}$ & $\mathbf{P}$ & $\mathbf{S}$ & $\mathbf{K}$ & $\mathbf{C a}$ \\
\hline 3.3 & 52 & 1.9 & 9.4 & 23 & 0.11 & 0.05 & 1.6 & 1.1 \\
\hline
\end{tabular}

TABLE II. pH and Ion Content of Soil Extract Solution.

\begin{tabular}{|c|c|c|c|c|c|c|c|c|}
\hline \multirow{2}{*}{$\begin{array}{c}\text { pH } \\
\left({ }^{\circ} \mathbf{C}\right)\end{array}$} & \multicolumn{8}{|c|}{ Ion Amounts, mg/100 g Soil } \\
\hline & $\mathrm{Cl}^{-}$ & $\mathrm{SO}_{4}^{2-}$ & $\mathrm{Na}^{+}$ & $F^{-}$ & $\mathrm{NO}_{2}^{-}$ & $\mathrm{NO}_{3}^{-}$ & $\boldsymbol{K}^{+}$ & $\mathrm{NH}_{4}^{+}$ \\
\hline $\begin{array}{c}6.75 \\
(20.7)\end{array}$ & 1.6 & 6.9 & 2.0 & 0.1 & $<0.03$ & 7.6 & 0.3 & $<0.03$ \\
\hline
\end{tabular}

\section{Macrocell Current and Spontaneous Potential Measurements}

The schematics of the electrodes for macrocell current measurement and the circuit of measurement are shown in Figure 2. The electrodes of two tops were set in air. To measure macrocell current, the electrodes were connected to a pair of shunts, each with a resistance of $100 \Omega$, and short circuited. The voltage at both ends of the shunts was measured every $30 \mathrm{~s}$, and the corresponding current was calculated using Ohm's law. The short circuiting of the electrodes was stopped every $1 \mathrm{~h}$. Then, the spontaneous potentials of the electrodes versus the copper-copper sulfate electrode (CSE) were measured.

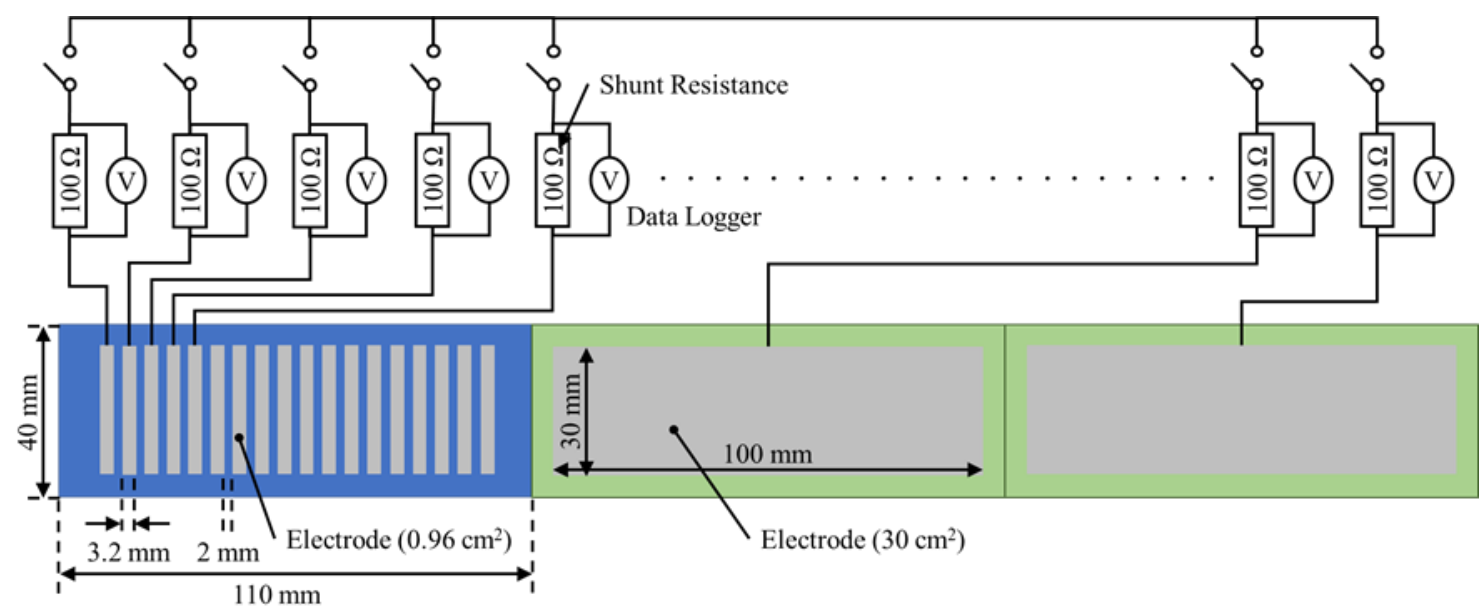

Figure 2. Electrodes used for macrocell current measurement and measurement circuit.

\section{$\underline{\text { AC Impedance Measurement }}$}

AC impedance was measured using the electrode that placed two carbon steel of $1 \mathrm{~cm}$ $\times 1 \mathrm{~cm}$ placed at a distance of $2 \mathrm{~mm}$. The frequency range was $1 \mathrm{mHz}-100 \mathrm{kHz}$, with a potential amplitude of $20 \mathrm{mV}$. The measurement was conducted at depths of $30 \mathrm{~mm}, 130$ $\mathrm{mm}$, and $230 \mathrm{~mm}$. Soil resistance and charge transfer resistance were evaluated using the measurement results.

\section{Water Ratio Measurement}

The conductivity and water ratio in soil were measured every $30 \mathrm{~s}$ using a sensor (WD3 -WET-5E of ARP) at depths of $30 \mathrm{~mm}, 130 \mathrm{~mm}$, and $230 \mathrm{~mm}$. 


\section{Corrosion Weight Loss}

Corrosion weight loss was measured using the test pieces shown in Figure 3 at different depths (from ground surface to depth of approximately $300 \mathrm{~mm}$ every $3.2 \mathrm{~mm}$ ). These test pieces were alternately short circuited and not short circuited to an aluminum rod. The test pieces of two tops were set in air. Corrosion weight loss was measured after the complete dissolution of the rust layer by immersion in a diammonium hydrogen citrate solution.

a)

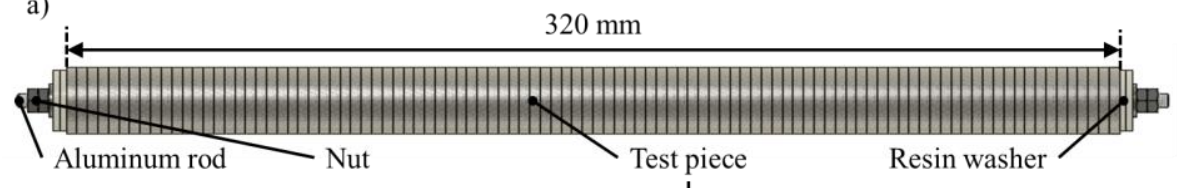

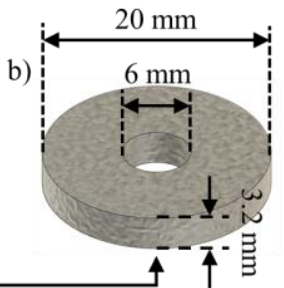

Figure 3. Schematics of a) pile and b) test piece for corrosion weight loss measurement.

\section{Results}

Changes in Water Ratio and Conductivity with Time

The changes in the water ratio and conductivity with time at each depth are shown in Figure 4. The water ratio and conductivity increased with the addition of ionized water. In addition, the trends of the changes in the water ratio and conductivity were similar. Ionized water was not added after March 7 because ionized water added on the day before did not dry and accumulated on the ground surface. In addition, the water ratios at each depth decreased at approximately constant rates for approximately two weeks after March 7.
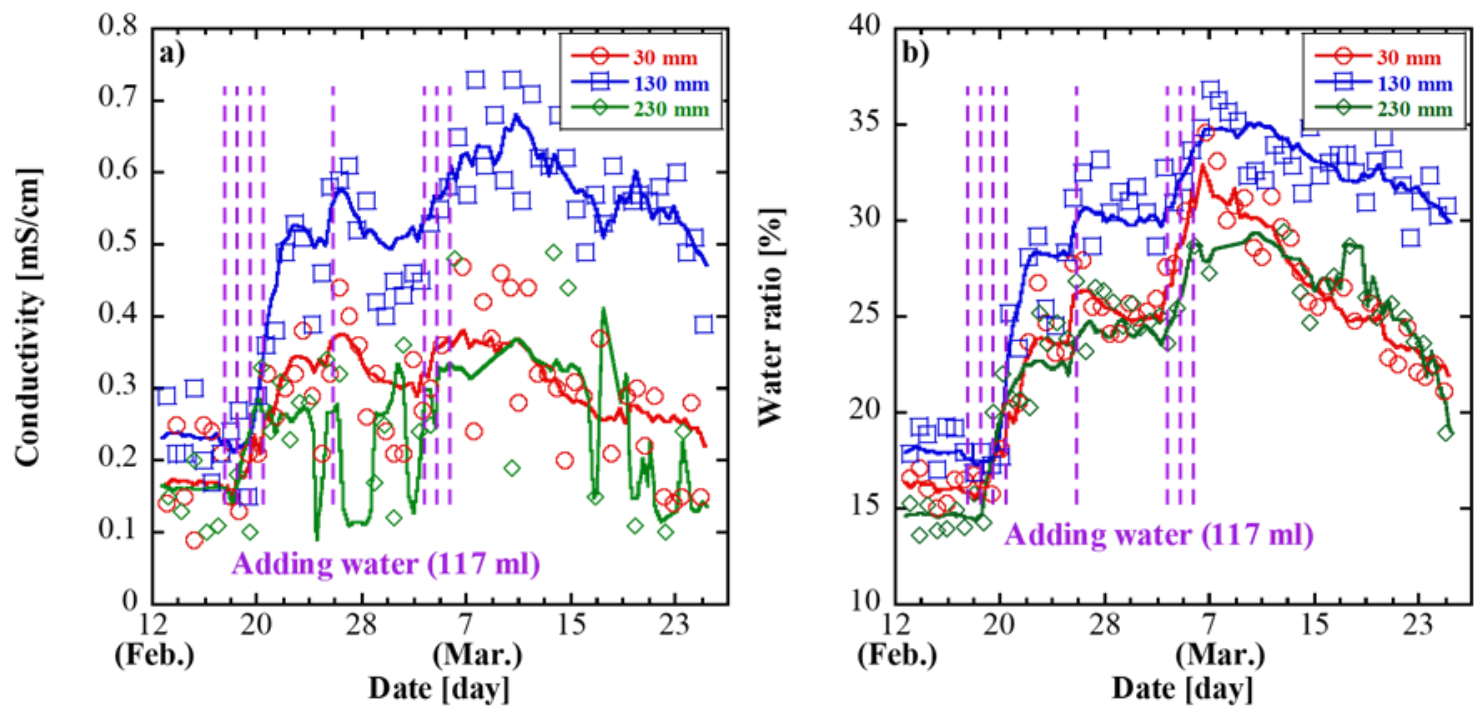

Figure 4. Changes in a) conductivity and b) water ratio with time.

\section{$\underline{\text { Macrocell Current Density and Spontaneous Potential }}$}

The changes in spontaneous potential and macrocell current density with time at each depth are shown in Figure 5. The experimental duration was divided into three periods. In the first (moisturizing period), the added ionized water infiltrated into soil. In the second 
period (flooded period), the added ionized water accumulated in soil. In the third period (drying period), ionized water was not added to soil. In the moisturizing period immediately after the start of the experiment, the potentials of the electrodes around the ground surface (depths: $0.0 \mathrm{~mm}, 5.2 \mathrm{~mm}$, and $10.4 \mathrm{~mm}$ ) were lower than those of the other electrodes. In addition, anodic current flowed in the electrodes around the ground surface. In the flooded period, the difference between the potentials of the electrodes was negligible. Moreover, there was no flow of macrocell current. However, the potential of the electrodes around the ground surface (depth: $0.0 \mathrm{~mm}$ ) was approximately $30 \mathrm{mV}$ higher than that of the other electrodes. Therefore, it appeared that cathodic current flowed in the electrodes around the ground surface. In the drying period, the potentials of the electrodes increased gradually. However, the rates of increase in the potentials were not constant, and the rates for the electrodes at depths of $20.8 \mathrm{~mm}$ to $36.4 \mathrm{~mm}$ were higher than those for the other electrodes. Therefore, anodic current flowed in the electrodes with relatively lower potentials (depths: $0.0 \mathrm{~mm}$ and $41.6 \mathrm{~mm}$ ).
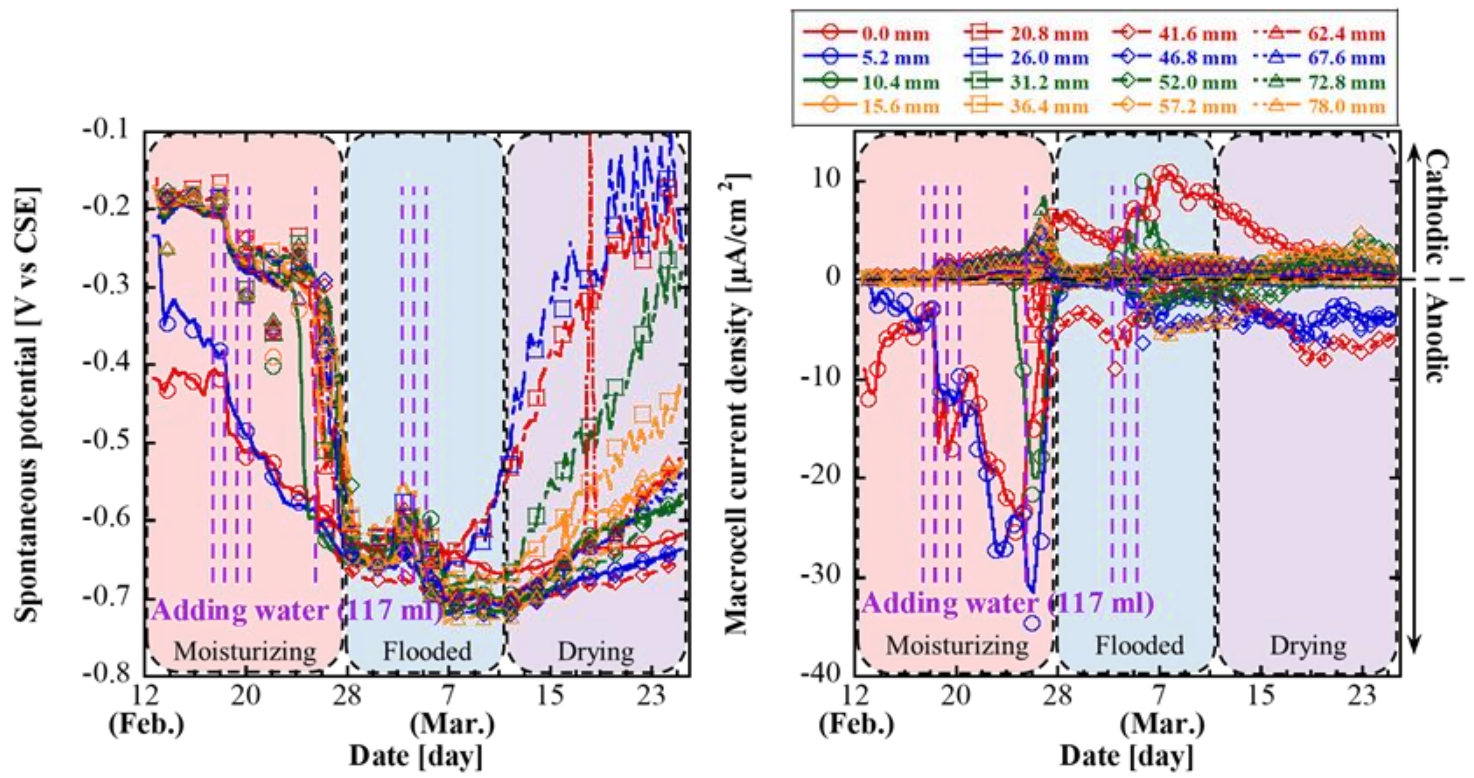

Figure 5. Changes in a) spontaneous potential and b) macrocell current density with time at each depth.

\section{Changes in Charge Transfer Resistance And Soil Resistance with Time}

The changes in charge transfer resistance and soil resistance with time estimated based on AC impedance measurement at each depth are shown in Figure 6. The conductivity measured by the sensor depended on the water ratio. However, soil resistance did not depend on the water ratio, and it was in the range of 500-1000 $\Omega$. The charge transfer resistance measured at a shallow depth (depth: $30 \mathrm{~mm}$ ) decreased as the water ratio increased. Similar trends were observed for the charge transfer resistance measured at deep depths (depth: $130 \mathrm{~mm}$ and $230 \mathrm{~mm}$ ). However, the change in resistance was small. As the minimum charge transfer resistance at each depth was approximately $700 \Omega$, the corrosivity at shallow depth was relatively lower than that at deep depths. 

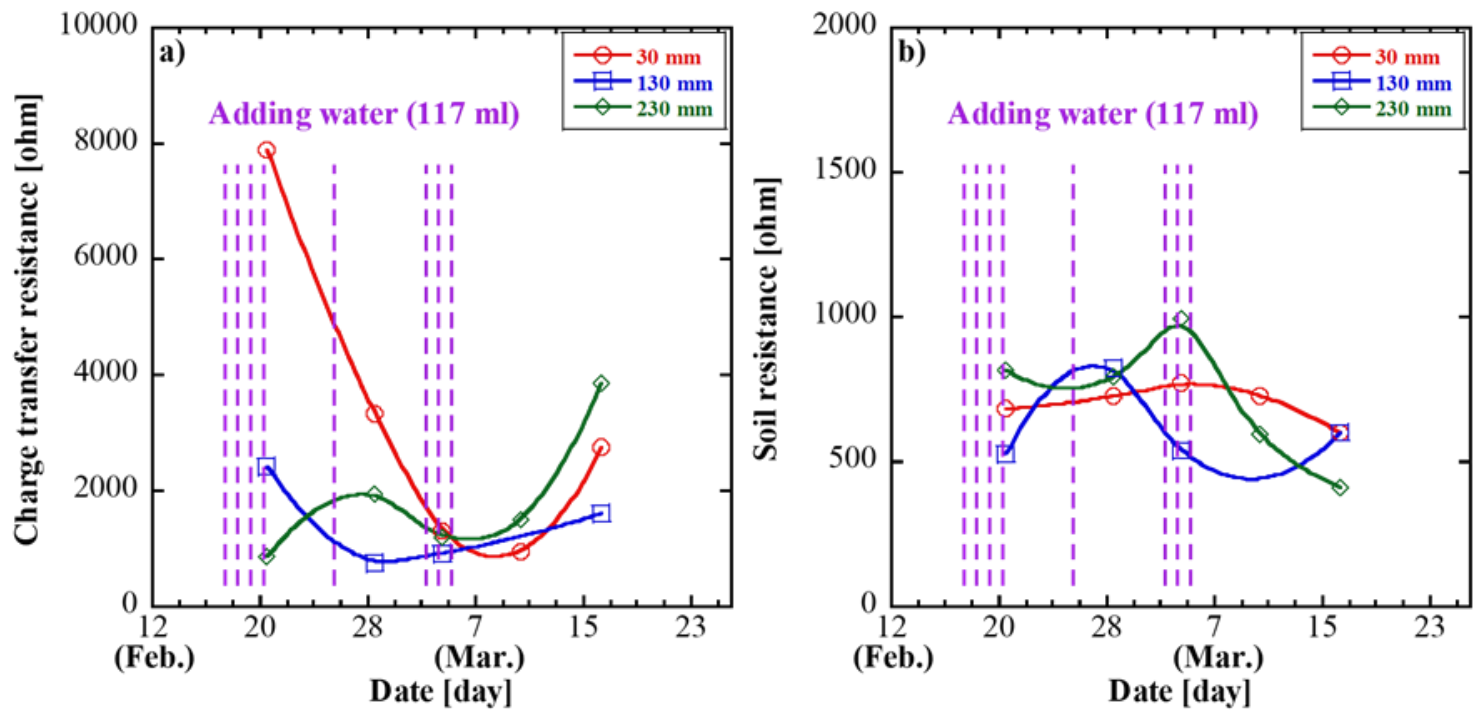

Figure 6. Changes in a) charge transfer resistance and b) soil resistance with time at each depth.

\section{Corrosion Rates Estimated by Macrocell Current Density and Weight Loss}

The corrosion rates at each depth, estimated based on macrocell current density and weight loss, are shown in Figure 7. Anodic current mainly flowed through the electrode around the ground surface (depth: $5.2 \mathrm{~mm}$ ). In the macrocell current, generally, the place that flowed anodic current corrodes instead of one that flowed cathodic current. Therefore, the corrosion rate of this electrode estimated using macrocell current density was extremely high. The corrosion rate estimated using the weight loss around the ground surface was the highest. Based on these results, it is considered that macrocell current influences the corrosion rate.
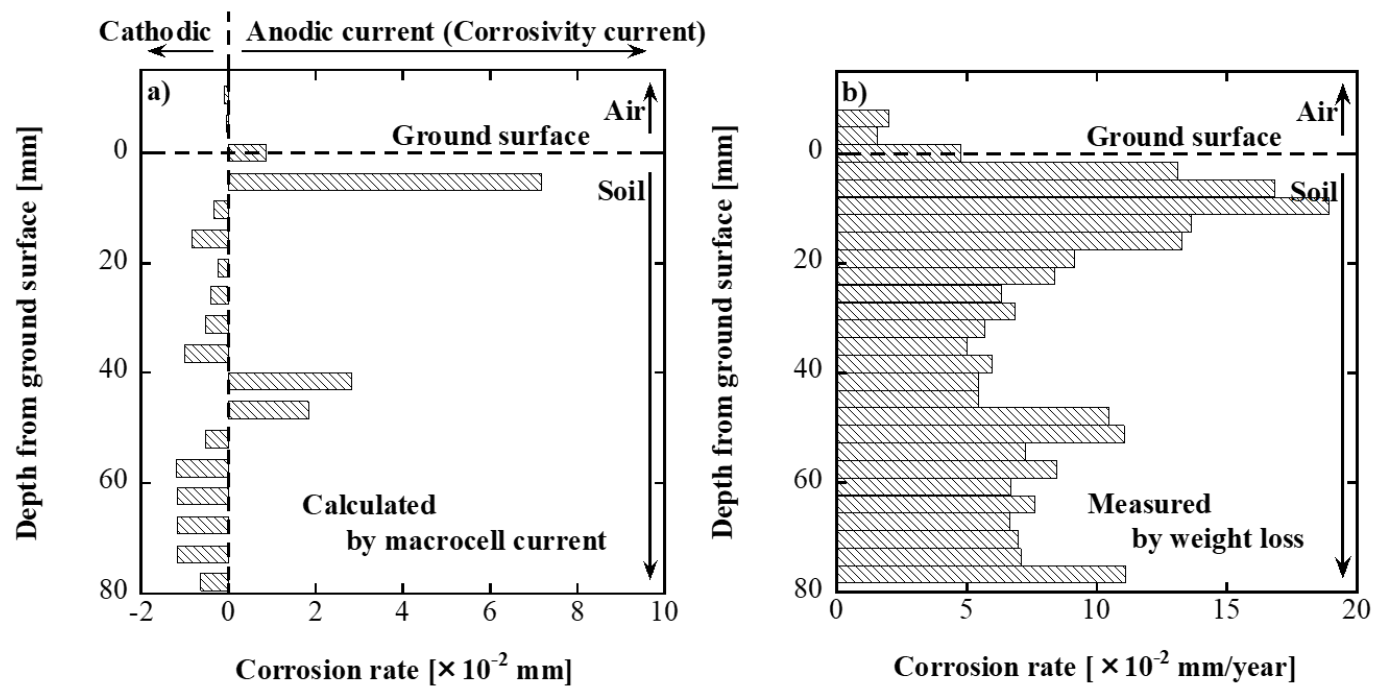

Figure 7. Corrosion rates estimated using a) macrocell current and b) weight loss at each depth. 


\section{Discussion}

We examined the spontaneous potential difference $(\Delta \mathrm{E})$ between two electrodes based on the oxygen concentration difference. According to the Nernst equation, this potential difference based on a four-electron oxygen redox in soil is predicted as follows:

$$
\Delta \mathrm{E}=\mathrm{RT} / 4 \mathrm{~F} \ln \left(\alpha_{1} / \alpha_{2}\right)
$$

where R, T, and F are the gas constant, absolute temperature, and Faraday's constant, respectively. $\alpha 1$ and $\alpha 2$ are the dissolved oxygen activity at the sides of the cathodic and anodic electrodes, respectively. At this point, if it is assumed that the dissolved oxygen activity is the dissolved oxygen concentration, then the potential difference is predicted as follows according to Henry's law:

$$
\Delta \mathrm{E}=\mathrm{RT} / 4 \mathrm{~F} \ln \left(\mathrm{P}_{1}\left(\mathrm{O}_{2}\right) / \mathrm{P}_{2}\left(\mathrm{O}_{2}\right)\right)
$$

where $\mathrm{P}_{1}\left(\mathrm{O}_{2}\right)$ and $\mathrm{P}_{2}\left(\mathrm{O}_{2}\right)$ are the oxygen partial pressures at the sides of the cathodic and anodic electrodes, respectively.

Generally, the oxygen partial pressure in air is approximately $0.2 \mathrm{~atm}$. If the oxygen partial pressure in soil becomes $0.002 \mathrm{~atm}$ because the diffusion of air is inhibited, the spontaneous potential difference is approximately $30 \mathrm{mV}$. The changes in the spontaneous potential difference with time between the maximum and minimum values at each depth are shown Figure 8. The spontaneous potential differences were clearly larger than the theoretically calculated value $(30 \mathrm{mV})$ throughout the experiment, except in the flooded period. This may be because the potential differences in the Moisturizing period and drying period are caused by reasons other than the dissolved oxygen concentration difference. Therefore, it appears that the potential difference and macrocell current caused by the gradient of soil aeration do not contribute significantly to soil corrosion around the ground surface.

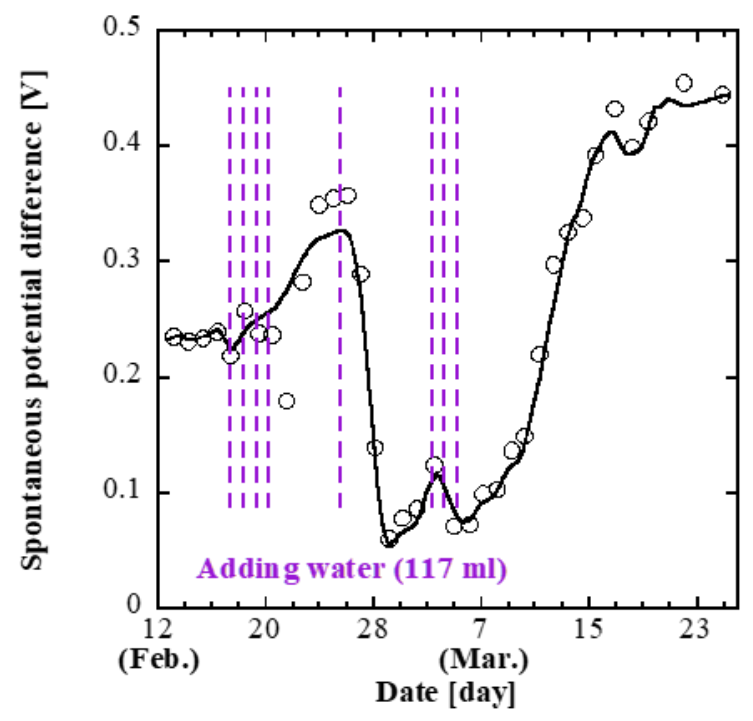

Figure 8. Change in spontaneous potential difference with time between maximum and minimum values. 


\section{Conclusions}

This report presented the results of the experimental investigation of the soil corrosion around the ground surface caused by the gradient of soil aeration. The experimental equipment simulated the top of a steel pile exposed to the atmosphere and around the ground surface in paddy soil. The spontaneous potential, macrocell current, and corrosion weight loss in soil were obtained at different depths.

Anodic current primarily flowed through the electrode around the ground surface in soil. The corrosion rates estimated using the weight loss around the ground surface were the highest. Based on these results, it is considered that macrocell current influences soil corrosion around the ground surface. The measured spontaneous potential differences were clearly larger than the theoretically calculated value $(30 \mathrm{mV})$. Therefore, it appears that the potential difference and macrocell current caused by the gradient of soil aeration do not contribute significantly to soil corrosion around the ground surface.

\section{References}

1. Y. Ohsaki, Soils Found., 22(3), 57 (1982).

2. K. Fujihashi, M. Okuji, W. Oshikawa, A. Tahara, T, Shinohara, and H. Katayama, Zairyo-to-Kankyo, 67(5), 216 (2018). 